\title{
THE BASIC PRINCIPLES OF THE PROCESS APPROACH IN THE FORMATION OF THE ORGANIZATIONAL ARCHITECTURE OF TRADING ENTERPRISES
}

\author{
Dmytro Onashchenko'
}

\begin{abstract}
The purpose of the article is to define and substantiate the basic principles of the process approach, as well as the stages of its use in the formation of the organizational architecture of trading enterprises based on the process approach. Continuing changes in the world economy associated with its globalization, as well as its crisis nature, growing competition in all spheres of the economy and especially in the field of trade, the owners and managers of each enterprise raise the urgent question: how to survive and what to do in this situation? What actions to take and what management tools to rely on to make life-changing business decisions? Methodology. During the analysis, the features of the process approach were considered when using it to form the organizational architecture of an enterprise, the essence, features and classification of business processes of an enterprise. Results. Shrinking most markets requires businesses to not only offer products that have the greatest value to customers, but also create variations of that product for different consumer segments, and make the necessary internal changes. The process approach to the formation of the organizational architecture of the enterprise and the enterprise management system offers a solution based on a simple mechanism - a business process, the task of which is to create value for the client. In addition, the process approach allows enterprises to maintain the required speed and efficiency of their activities. For in modern conditions of a high level of competition between enterprises, it is very important to focus on key customers, determine their requirements and criteria for evaluating the results of the processes performed by the company), quickly organize processes and ensure their parameters in accordance with consumer expectations. Practical implications. Analysis of the features of the process approach when using it to form the organizational architecture of an enterprise, the essence and features of business processes made it possible to conclude that they really contribute to the establishment of effective and flexible activities of the enterprise, increase the competitiveness of the enterprise in the market compared with other enterprises. Value/originality. The use of system analysis made it possible to formulate the features of the application of the process approach in modeling, improving the organizational architecture of trading enterprises
\end{abstract}

Key words: trading enterprise, enterprise architecture, process approach, business processes, principle.

JEL Classification: D23, L22

\section{Introduction}

Changes in technology, markets and customer needs have become commonplace in today's economy, and commercial enterprises, seeking to maintain their competitiveness, are forced to use increasingly relevant technologies to improve the fundamentals of their activities. This is due to the fact that traditional methods of doing business for trading enterprises become ineffective due to the following factors: slowing down the growth of consumer demand, increased competition, slowing growth of net revenue, increasing the cost of debt

\footnotetext{
Corresponding author:

${ }^{1}$ Interregional Academy of Personnel Management, Ukraine.

E-mail: dmytroonashchenko@gmail.com

ORCID: https://orcid.org/0000-0002-9991-4798
}

service. In addition, the key ability for long-term success of the enterprise is the ability to create and develop competitive products in a changing environment. The speed of change and efficiency of the enterprise come to the fore. In the long run, companies no longer compete with business models or products, but with organizational systems that can, in turn, effectively transform business models and create innovative products. An additional complication in modern enterprises is that the processes are broken down into small operations and individual tasks and attention is lost 
on the overall result that the customer expects to receive. There is an interesting effect, in the same company, at the level of individual operations, the company can work in process logic, but as soon as we begin to collect operations in larger processes, process logic is broken and gradually turns into a functional hierarchy, which loses most of the necessary connections. As a result, end-to-end processes of a larger order do not have owners and are divided between a large number of functional units, losing sight of the client and the overall result that must be created for him or her. The enterprise from a horizontal chain of processes turns into a vertical hierarchy of functions.

In this regard, many market players have begun to look for ways to improve the efficiency of their business. One of these tools was the use of a process approach to improve business processes and organizational architecture of the enterprise, which in combination with cost optimization and the introduction of modern information technology can bring the enterprise to a new level. The process approach to organizational modeling is becoming a leading practice in the world, allowing companies to obtain the necessary speed, efficiency and adaptability. According to A. Bjorn, "the process approach was much more effective than functional in terms of the struggle for competitiveness in a dynamic consumer market with its unpredictable whims and somersaults" (Bjorn, 2003).

\section{Theoretical and methodological principles of the process approach}

In developed countries, process organizational modeling has become common practice. The transition to a process approach to the formation of the organizational architecture of the enterprise means the transition to activity management, in contrast to the management of structures, which is characteristic of functional management. The functional approach to building an organizational architecture has a number of insurmountable limitations, which in conditions of high competition and requirements for flexibility and efficiency does not allow organizations to function successfully. "Today's companies consist of functional mines or chimneys, vertical structures based on small elements of processes" (Hammer, 1997). The key limitations of the functional approach are:

1. Local optimum. Everyone does their job in the best way, and all this can be counterproductive, as there is no guarantee that local optimization is beneficial to the process as a whole;

2. Internal client - manager. Those who must be real domestic consumers are isolated from each other;

3. Purpose in the hierarchy: personal security, self-preservation in the system, meeting the requirements of the leader, career advancement. One of the consequences is distorted information upstairs;

4. Time of interaction between divisions: $20 \%-$ for performance of work and $80 \%$ for transfer of its results to the following executor;

5. Focus on the task does not stimulate employee interest in the end result;

6. No one sees the big picture. No one understands how an organization actually works.

The process approach overcomes these limitations and creates a real competitive advantage. The view of the enterprise through business processes overcomes the boundaries of the functional division of labor. There are integral blocks of work that must be done to create a product. They require a certain set of competencies, which may not coincide with accepted functional practice. Everyone is guided by the added value that must be created in the business process and only under it is selected the necessary qualifications of performers. The advantages of using a process approach are as follows:

1. The company becomes more flexible and adaptable;

2. It is clear who is responsible for what and how each operation affects the end result;

3. The relationship "customer - service provider" set up horizontal links throughout the chain, and create the effect of "pulling";

4. It simplifies the management system, less hierarchy, more subordinates, increasing the speed of decision-making;

5. It becomes possible to manage key business processes and results of the enterprise, as well as to integrate, often disparate, the actions of departments and direct their efforts to a single result;

6. The organization does not need heroes, ordinary employees become productive in the system;

7. Stages of the process are performed in a natural manner;

8. Processes have many options for execution, focusing not on tasks, but on the value result for the client; 
9. The work is performed where it is possible to do it most effectively, and not where it is determined by the functional structure;

10. The volume of inspections and control is reduced;

11. The need for approvals is minimized.

The process approach has been developed and applied in order to create horizontal links in organizations. Units and employees involved in one process can independently coordinate the work within the process and solve emerging problems without the involvement of senior management. The process approach to management allows us to solve the arising questions more quickly and to influence the result. Due to the international standards of the ISO 9001: 2000 series, the process approach is a generally accepted norm in the activity of enterprises. And the basic principles on which the process approach is based include the following:

- the principle of interconnection of processes, which is based on the fact that the company is a network of processes that represent any activity of the company, where various works are performed; - the principle of demand for the process, which is based on the fact that each process has a specific purpose, and the results of this process are in demand by the relevant consumer;

- the principle of documenting processes, which is based on the fact that the process activities must be documented, due to which there is a further standardization of the process and a basis for change and further improvement of the process. In addition, the description of business processes provides transparency of all business operations, allows you to analyze the possible consequences of failures at a particular stage of work, timely find and correct errors, which, in turn, implements the most important idea of quality management embedding quality in the process (instead of total quality control of finished products);

- the principle of process control, which is based on the fact that each process has a beginning and an end, and within these limits should be defined indicators that characterize the process and its results;

- the principle of responsibility for the process, which is based on the fact that to perform a certain process may involve different specialists and employees of the enterprise, while the responsibility for the process and its results rests with a certain person.

\section{Business process as a key element of the process approach}

Based on the fact that in the process approach, any enterprise is considered as a business system, which is a connected set of business processes, its key element is the business process. According to ISO 9001 standards, a business process is "a set of interconnected and interacting activities that will turn inputs into outputs". At the same time, in a broader sense, the business process can be defined as a sequence of actions to carry out production and economic activities within a certain organizational management structure of an industrial enterprise, which converts the "input" of resources to "output" the result, which has value for the consumer. This business process is characterized by two important features: firstly, it has its external suppliers, internal recipients and consumers; secondly, it crosses organizational boundaries, i.e. it usually flows over the barriers that exist between units of the organization, as well as between different organizations, interconnected relations "supplier-consumer" or even penetrates these barriers (Tashkinov, 2014).

Given the importance of this category, even despite generally accepted standards, it does not have a single universal definition, and among the main characteristics that are used in its definition, the following are used:

- sequence;

- action;

- set;

- activity;

- result;

- value;

- consumer

and others.

Using these characteristics, as well as taking into account the features and essence of the business process, we concluded that the business process is a set of certain actions within the relevant organizational structure, which forms the overall business system of the enterprise to achieve primary goals.

One of the main stages of building a process organization of the enterprise is the selection and classification of business processes. There are a large number of different classifications of business processes, but according to the results of the study and generalization, we will focus on the following basic categories: 
- main business processes - focused on the production of products or services that have value for the customer, and that provide income for the company;

- ancillary business processes - designed to ensure the implementation of basic business processes. In general, they provide resources to all business processes of the enterprise;

- business management processes - cover the full range of management functions at the level of each business process and business system as a whole, i.e. the interconnected set of all business processes of the enterprise. The construction of the technology of management processes is based on the concept of controlling, which allows to form a complete cycle of enterprise management, from strategic planning to analysis of the causes of deviations from the plan and the formation of management influences.

From this definition we can conclude that the whole set of interacting business processes of a particular enterprise forms a business system of the enterprise, which covers all activities of the enterprise. In this case, business processes exist in inseparable connection with KPIs and for efficient operation require accurate and efficient calculation, which is one of the fundamental differences between the process approach and the functional one. The process approach is based on the maximum expressed by P. Drucker: "You can only manage what can be measured." Measuring and interpreting the value result of each business process forms an effective relationship between the internal customer and the service provider.

\section{Features of project management of an enterprise}

The application of the process approach in different areas of the economy to obtain the greatest efficiency requires consideration of their main features, and this is especially true in such areas as trade. According to the system approach, which is presented in the works of N. Novoselova, all business processes of a trading company are divided into three groups:

1) managing business processes that control the functioning of the system. Examples of the management process are corporate governance and strategic management;

2) operating business processes that make up the main business of the company and create the main revenue stream. Examples of operational business processes are supply, production, marketing and sales;

3) support business processes that serve the core business. For example, accounting, recruitment, technical support (Novoselova, 2009).

All three groups of processes are interconnected and separately from each other they cannot bring high efficiency.

In the traditional approach, among the main business processes of a trading company are listed the main operating processes of a trading company, such as sales of goods, transportation, etc., and there are other groups than in the system approach. Based on the functions, business processes of a trading company are divided into:

a) commercial (advertising of goods and services, selection and ordering of goods from suppliers, pricing, advising customers, selection of products, sale of goods);

b) technological business processes of trading organization, which include such processes (Vinogradova, 2012):

- transportation of goods from suppliers;

- acceptance, storage of goods;

- moving goods from the warehouse to the trading floor;

- sorting of goods and preparation for sale, packaging, etc .;

- organization of sales of goods;

- inventory;

- merchandising, etc.

Because a trading company is a complex system, its activities consist of a large number of business processes, each of which is a sequence of actions and decisions aimed at achieving a specific goal. Each company has its own set of business processes, and it is not standard for all trading companies, as it depends on the specifics of the trading company (industry, size, location, nature of sales, etc.).

For the effective functioning of a trading company in market conditions, it must be constantly evolving and improving. To do this, when applying the process approach, it is first necessary to determine and assess how well the business processes of the enterprise are functioning, which will identify not only shortcomings and weaknesses, but also possible areas for business processes and architecture of the trading company. The efficiency of this process is increased through the use of key performance indicators of business processes of a trading company. 
In general, obtaining data to assess the business processes of trade requires three main steps:

1) indicator planning and development of tools, procedures and criteria for data collection;

2) direct data collection;

3) data analysis and reporting based on the results of the analysis (Dashkov, Pambukhchiyants, 2010).

As for the indicators that most fully reflect the efficiency of business processes of commercial enterprises, they should include:

- productivity;

- cost level;

- quality.

At the same time, depending on the characteristics of the trading company, this list of indicators can be increased.

Based on the results of assessing the effectiveness of commercial activities and conducting a qualitative assessment of the implementation of regulations of the trade and technological process of surveyed enterprises identify weaknesses in the business processes and organizational architecture of the enterprise, which serves as a basis for modeling new or improved organizational architecture, etc.

\section{Conclusions}

Process organizations look for reasons for not achieving goals in business processes, rather than focusing on blaming employees. This allows you to solve problems and not build up internal tension in work teams.

The modern development of information and communication technologies gives an additional incentive to use the process approach in the organization. The process organization is based not on individual structural elements, but on the connections between them. The essence of connections lies in the ability of participants to communicate with each other. For communication to be effective, it must be data driven. Thus, the ability to establish effective communication between business processes becomes a key factor in the success of a process organization. Information technologies make it possible to collect and operate with a large amount of data, business intelligence systems greatly simplify access to them, and modern communication tools neutralize physical remoteness. The process approach completely changes the paradigm of modern enterprise management by offering a holistic, versatile and scalable solution that can create a long-term competitive advantage for companies in today's world.

Thus, the introduction and use of a process approach to the formation and improvement of the organizational architecture of the trading company will have the following positive consequences for the trading company:

1. Changing the culture of doing business in general. Lack of systematization in the organization and management of business processes; the use of software products designed to model business processes, raises issues of organizational structure and architecture of commercial enterprises.

2. The process approach promotes the formation of new economic thinking of the management of trading enterprises, focused on modern management methods that allow to ensure the investment of the range of trade networks in the range of the region, the effectiveness of trade and high service culture.

3. The application of the process approach requires certain investments; optimization of temporary, material, labor, information resources. But the structured goals and objectives of trade, standardization of business processes will contribute to further economic growth of trading enterprises and their efficiency.

\section{References:}

Bjorn, A. (2003). Business processes. Improvement tools. Moscow: RIA "Standards and Quality".

Hammer, M. (1997). Corporation Reengineering. Manifesto for a revolution in business. Saint Petersburg: Saint Petersburg University.

Tashkinov, A. G. (2014). Theoretical and methodological foundations of the process approach to management at an industrial enterprise. Bulletin of the Perm University, vol. 2(21), pp. 77-86.

Novoselova, N. V. (2009). Standardization of business processes in retail. Store Management, vol. 9, pp. 15-23.

Vinogradova, E. V. (2012). Features of business processes of management of trading enterprises. Bulletin of Donetsk State University of Economics and Trade, vol. 4, pp. 22-27.

Dashkov, L. P., \& Pambukhchiyants, V. K. (2010). Commerce and trade technology. Moscow: Information and Implementation Center "Marketing". 